\title{
Skin Care Habits of Dermatology Patients in Yaounde - Cameroon
}

\author{
Anne Cécile Zoung-Kanyi Bissek ${ }^{1}$, Guillaume Chaby ${ }^{2}$, Earnest N. Tabah ${ }^{1}$, Emmanuel Kouotou ${ }^{1}$, \\ Julius Y. Fonsah ${ }^{1}$, Catherine Lok ${ }^{2}$, Alfred K. Njamnshi ${ }^{*}, 1$, Paul Koueke ${ }^{1}$ and Walinjom F.T. Muna ${ }^{1}$ \\ ${ }^{I}$ Department of Internal Medicine and Specialties (Dermatology \& Neurology Units), Faculty of Medicine \& Biomedical \\ Sciences, University of Yaoundé I, Yaoundé, Cameroon \\ ${ }^{2}$ Centre Hospitalier Universitaire, Amiens Sud, France
}

\begin{abstract}
Introduction: Black and satinee skin has been a beauty quality in our environment. Then bleaching became very popular in our communities but not much is known about skin habits. The objective of this study was to identify skin care habits of patients in Yaoundé.

Patients and Methods: This study took place in the dermatology clinic of the Yaounde General Hospital, including all patients seen from October 2001 to September 2002. The skin care habits were compared with respect to sex and age. The level of statistical significance was $\mathrm{p}<5 \%$.

Results: During the study period, 714 medical files (418 females and 296 males) were reviewed. In men as well as in women, savon de Marseille and antiseptic soap were respectively the first and second most used bathing soaps. However, women had a statistically significant preference for bleaching, super fat and exfoliative soaps (78.0\% vs $22.0 \%, 69.0 \%$ vs $31.0 \%, 87.0 \%$ vs $13.0 \%$ ) with respect to men. Users of antiseptic soaps had eczemas (35\%). Only $16.0 \%$ of women did not apply daily body lotions as against $84 \%$ of men $(\mathrm{p}=0.0001)$. The use of bleaching lotion $(13 \%$ overall) was clearly more widespread in women than in men $(87.0 \% v s 13.0 \% ; \mathrm{p}=0.0001)$. The use of topical corticosteroids was associated with acne.

Conclusion: A relatively high proportion of our patients use bleaching products and antiseptic soaps. The use of antiseptic soaps and the additional of topical steroids in commercial preparations may become a serious health problem if left uncontrolled.
\end{abstract}

Keywords: Skin care, black, bleaching.

\section{INTRODUCTION}

Black, bright and satinee skin used to be a beauty criterion in our environment. Smith et al. declare in an article on hair and skin care in black children, that the skin and hair that were well appreciated before the time of slavery had lost their value after the contact with the whites [1]. Progressively, the desire for skin bleaching by African Americans in the USA and later in African populations became widespread throughout the black population, reaching prevalences of $80 \%$ in some African towns [1-3]. Skin bleaching then became a sign of well being for those who practiced it.

Bleaching has thus become a very popular practice in several communities, in spite of its many well known side effects. Besides skin bleaching, other habits which appear to be less dangerous should equally be of interest to health practitioners in our context in order to promote good cosmetologic practices. The objective of this work was to identify the different skin care habits of patients received at the dermatology outpatient clinic in the Yaoundé General Hospital.

*Address correspondence to this author at the Department of Internal Medicine (Dermatology \& Neurology Units), Faculty of Medicine \& Biomedical Sciences, University of Yaoundé I, Yaoundé, Cameroon; Tel: +237 76199 64; Fax: +237 2231 12 24; E-mail: aknjamnshi@yahoo.co.uk

\section{PATIENTS AND METHODS}

The survey was done at the Yaoundé General Hospital. We reviewed 714 files of all patients consecutively received at the dermatology outpatient consultation either on appointment or as an emergency, during the period from October 2001 to September 2002. The main inclusion criterion was any patient presenting with a skin problem at the dermatology outpatient clinic, irrespective of age or sex. The dermatology service of the Yaoundé General Hospital is one of the main departments of the teaching hospitals of Yaoundé, and has had a consultant dermatologist since 1999. All patients in this department were seen by the same dermatologist and data were systematically collected irrespective of the main complaint. The pathologic conditions observed were recorded according to the following groups: allergies, scars, systemic diseases, infections, sexually transmissible disease (STD) syndromes (genital ulceration, urethral discharge, vaginal discharge, scrotal swelling, lower abdominal pains), HIV infection, lichenification, disorders of epidermal appendages, disorders of epidermal differentiation, pigmentation disorders, tumours and others. The following variables were extracted from the case files for analysis: chief presenting complaint, sociodemographic data (age, sex), cosmotologic history (nature of body lotions and bathing soaps used on a daily basis). Any soap or body lotion prescribed during the medical consultation was considered as an integral 
part of the treatment and were thus not included as habitual use in the analysis.

The pharmacological composition of the soaps and body lotions was not taken into consideration for this study. Information collected from patients and vendors of cosmetic products facilitated the classification of products unknown to the dermatologist. The different soaps recorded were separated into seven types: savon de Marseille, antiseptic soaps, bleaching soaps, super fat soaps, ordinary soaps, exfoliative soaps and the unclassified. The term "ordinary soaps" groups all soaps with perfume, in solid or liquid form available in the market. The expression "savon de Marseille" referred to non perfumed neutral soaps. The nature of the soap was described as undetermined when no information concerning it could obtained.

The different products used to moisten or smoothen the skin were classified into 5 categories: pure glycerine, oils (palm kernel, palm, maize, olive, almond), dermo-cosmetic lotions, (specific non perfumed lotions, available only in the pharmacy), bleaching lotions (irrespective of the active ingredient), ordinary moisturing lotions (neither bleaching nor antiseptic, perfumed or not available in the open market). Any lotion was considered "indeterminate" if the patient did not know its nature. It was considered that there was "no lotion" when the patient was not applying any emollient or moisturizers after bathing and douching.

The extracted data were analysed using Epi Info version 6.0 for Windows (CDC Atlanta). Qualitative variables were expressed as frequencies or percentages. The cosmetologic habits of males were compared with those of females and also between different age groups and with reference to the chief presenting complaint using the $\mathrm{Chi}^{2}$ test. The level of statistical significance was set at $5 \%(\mathrm{p}<0,05)$.

\section{RESULTS}

Of 714 files studied $(59.0 \%$ female and $41.0 \%$ male) with ages varying from 6 weeks to 89 years, the five most frequent reasons for consultation in decreasing order were: pruritus (46.0\%), asymptomatic eruption (20\%), acne $(8.0 \%)$, pigmentary disorders $(6.0 \%)$ and pain $(5.0 \%)$. The five main diagnostic groupings recorded in decreasing order were: allergic reactions $(34.0 \%)$; infections $(20.0 \%)$; skin appendage disorders $(15.0 \%)$ and pigmentation disorders $(4.0 \%)$. The allergic conditions were dominated by eczema $(66.00 \%)$. Fungal infections were the most frequent $(32.0 \%)$ followed by parasitic infections $(28.0 \%)$ among all infectious conditions. Acne was the most frequent skin appendage condition recorded $(86.0 \%)$. Globally there was a statistically significant difference in the percentage of chief complaints in both sexes (see Table 1). More women than men had as chief complaint acne, pruritus and pigment disorders ( $\mathrm{p}=0.000001,0.008110,0.003900$ respectively) but more men than women consulted for scars and ulcerations ( $\mathrm{p}=0.028300$ and 0.000591 respectively).

Six types of bathing soaps were currently used, in the following decreasing order: savon de Marseille, antiseptic soap, bleaching soap, super soap, ordinary soap, and exfoliative soap. Savon de Marseille and antiseptic soap were the first and second choices respectively for men as well as for women. However, women had a statistically significant preference for bleaching, super fat, and exfoliative soaps $(78.0 \%$ vs $22.0 \%, \mathrm{p}=0.0435 ; 69.0 \%$ vs $31.0 \%, \mathrm{p}=0.0398 ; 87.0 \%$ vs $13.0 \%, \mathrm{p}=0.0008)$ with respect to men (Table 2 ).

Among all the case files reviewed, $11.06 \%$ of patients did not know the nature of the soap they used. In the group of those who knew the nature of the soap (635/714), savon de Marseille was the most preferred (53.0\%) and exfoliative soap the less preferred $(1.0 \%)$. The use of antiseptic soap (123) was introduced within the age-group $0-10$ years in $2.0 \%$ of the sample population with a knowledge of the nature of the soap (data not shown on table). Antiseptic soaps were most used by the 11-20 and 21-30 age groups (Table 3) and this represented $11.0 \%$ of the sample population with a knowledge of the nature of the soap. Users

Table 1. Chief Complaint as a Function of Sex

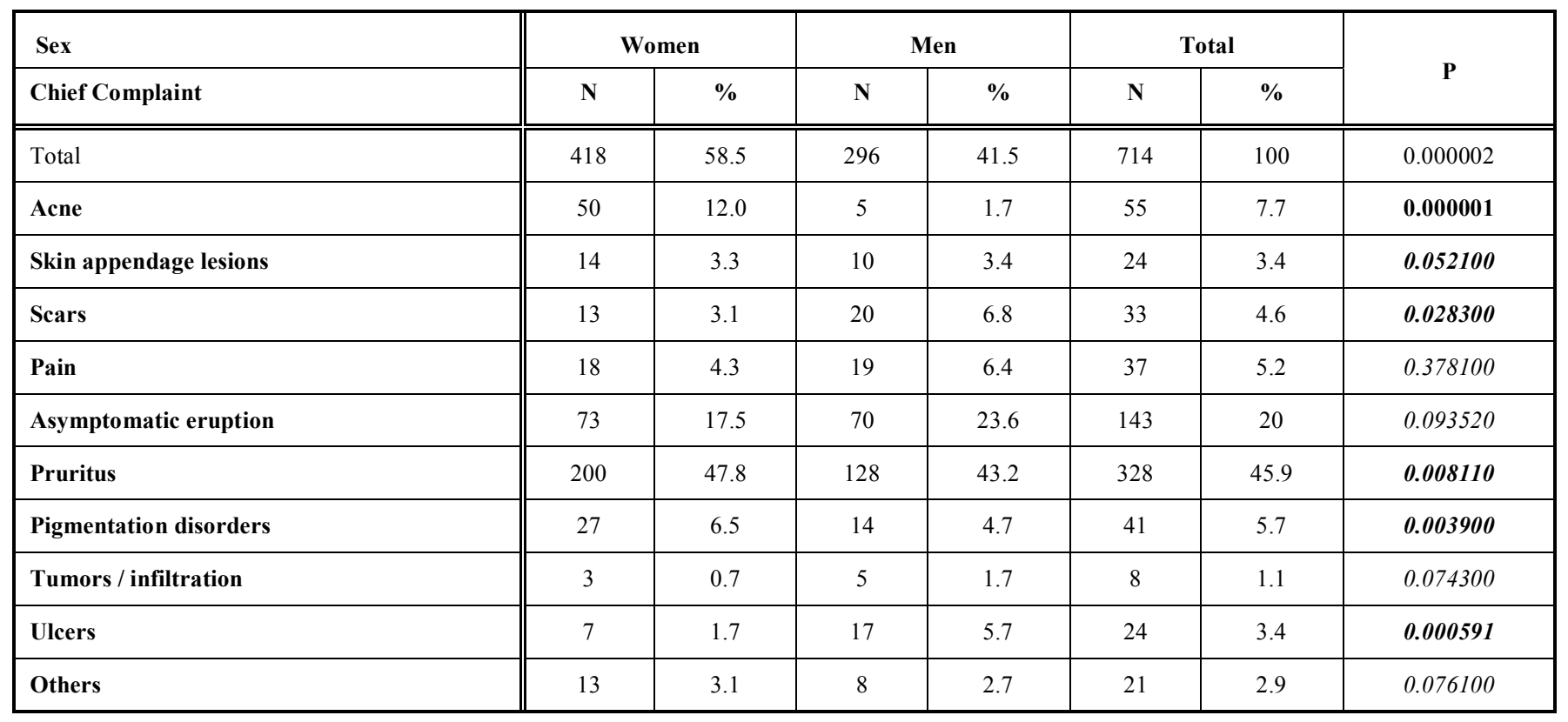


of antiseptic soap were found to have the following skin disorders (data not shown): 43 presented with allergies, of which 33 were eczemas; 4 cheloid scars; 1 systemic disease; 31 infections (5 fungal infections, 9 parasitic infections, 12 viral infections, 1 bacterial infections, 4 dermatophytoses); 2 STDs; 3 lichenification; 17 disorders of epidermal appendages (acne); 3 disorders of epidermal differentiation, 2 pigmentation disorders, 4 tumours and 17 others.

Table 2. Soap Using Habits of Patients with Respect to Sex

\begin{tabular}{|c|c|c|c|c|}
\hline Type of Soap & N & Female (\%) & Male (\%) & P Value \\
\hline \hline Total & 714 & 59 & 41 & \\
\hline Antiseptic soap & 123 & 60 & 40 & 0.1503 \\
\hline Exfoliative soap & 8 & 87 & 13 & $\mathbf{0 . 0 0 0 8}$ \\
\hline Savon de Marseille & 334 & 56 & 44 & 0.0576 \\
\hline Bleaching soap & 63 & 78 & 22 & $\mathbf{0 . 0 4 3 5}$ \\
\hline Ordinary soap & 52 & 58 & 42 & 0.0757 \\
\hline Super-fat soap & 55 & 69 & 31 & $\mathbf{0 . 0 3 9 8}$ \\
\hline Indeterminate soap & 79 & 42 & 58 & 0.0569 \\
\hline
\end{tabular}

Bleaching soap was also introduced early in life, within the age-group 0-10 years and mostly used by the age group 21 to 50 years. Super fat soap was mostly used for children less than 10 years (Table $\mathbf{3}$ ).

In the case files, $87.00 \%$ practiced daily body care after a bath, with a significant difference between men and women: only $16.0 \%$ of women do not apply daily body lotion as against $94.0 \%$ for men $(p=0.0001)$. The analysis of skin care habits showed in the two sexes a preference for ordinary moisturizing body milk ( $65 \%$ in women $v s 35.0 \%$ in men). The use of bleaching lotions was clearly more widespread in women than in men $(87.0 \%$ vs $30.0 \% ; \mathrm{p}=0.0004)$. Some patients $(1.8 \%)$ could not determine the nature of products used (Table 4).

The addition of some other substance into commercial moisturizers or emollient preparations was observed in $18.0 \%$ of cases (data not shown). Glycerin (13.0\%) and topical corticosteroids $(2.0 \%)$ were the substances most frequently added (data not shown). The other products added represented $3.0 \%(21 / 714)$ of the cases (data not shown).
Among the 714 case files, $13.0 \%$ of patients did not use any body lotion $(92 / 714)$. Within the group that used body lotion after a bath, $(\mathrm{n}=622), 12.0 \%$ did not know the nature of the lotion (Table 5). Ordinary moisturising lotions were the most used $(67.0 \%)$ while dermo cosmetic lotions were the least preferred $(1.0 \%)$. Bleaching lotions were introduced within the age-group $0-10$ years $(4.0 \%)$ and mostly used by the age group 21 to 30 years (24.0\%). The analysis of users of body moisturizers/emollients with respect to bathing soap type showed that $16.0 \%$ of those who habitually used antiseptic soaps did not apply any body lotion at all (Table 6). An analysis of chief presenting complaints and cosmetologic habits revealed that amongst patients who presented with acne, the proportion that added other products in their body lotion was significantly higher than those who did not, $\mathrm{p}=0.025$ (Table 7). Furthermore, it was observed that $63.0 \%$ added glycerin, $19.0 \%$ unspecified products and $13.0 \%$ topical corticosteroids (Table 8 ).

\section{DISCUSSION}

This is the first study in Cameroon focusing on skin care habits. It shows the importance of skin care habits amongst patients consulting for various skin problems. Our results reveal that the habitual use of antiseptic soap comes second place after savon de Marseille in Yaoundé. Furthermore, our data shows that antiseptic soap is introduced very early in life. It is well known that these products indiscriminately destroy the flora of the skin thereby modifying one of the defense mechanisms of the body against microbes, namely the saprophyte flora [6]. It is also well established that the prolonged use of antiseptic soap alters the protective hydrolipid film of the skin [6]. The combination of these two consequences of antiseptic soap use certainly modifies the physiology of the skin in the long term, fragilising and rendering it susceptible to further external aggression. This situation is even more serious given the early introduction of antiseptic soaps, before age 10 years, to physiologically immature skin of subjects in our environment. To the best of our knowledge, no longitudinal study has been conducted in Cameroon (and in sub Saharan Africa) to determine the long term effect of these practices on the skin.

Fitoussi and Cabotin had already reported the practice of aggressive and irritating body washing attitudes of Africans living in France [4]. In fact, these people habitually use detergents and antiseptics for bathing, and scrub the skin with exfoliative commercial or traditional sponges, scrubbing stone $[4,5]$. The observation of essentially

Table 3. Soap-Using Habits with Respect to Age $(n=635)$

\begin{tabular}{|c|c|c|c|c|c|c|c|}
\hline Age Group & $\mathbf{N}$ & Savon de Marseille (\%) & Antiseptic Soap (\%) & Exfoliative Soap (\%) & Ordinary Soap (\%) & Bleaching Soap (\%) & Super Fat Soap (\%) \\
\hline Total & 635 & 53 & 19 & 1 & 8 & 10 & 9 \\
\hline $0-10$ & 116 & 63 & 11 & 0 & 6 & 2 & 18 \\
\hline $11-20$ & 97 & 53 & 28 & 2 & 7 & 4 & 6 \\
\hline $21-30$ & 175 & 43 & 25 & 3 & 5 & 15 & 7 \\
\hline $31-40$ & 99 & 58 & 14 & 0 & 7 & 15 & 6 \\
\hline $41-50$ & 80 & 51 & 18 & 0 & 15 & 13 & 4 \\
\hline$>51$ & 68 & 53 & 16 & 0 & 15 & 7 & 9 \\
\hline
\end{tabular}


inflammatory skin disorders in this group has led to the development of the new concept of "adaptation pathology" described by these authors in dermatological practice on black skin in the temperate regions.

Table 4. The Distribution of Daily Skin Care with Moisturiser/ Emollient by Sex

\begin{tabular}{|c|c|c|c|c|}
\hline $\begin{array}{c}\text { Moisturizer/ } \\
\text { Emollient Use }\end{array}$ & $\mathbf{N}$ & Female (\%) & Male (\%) & P Value \\
\hline \hline Total & 714 & 59 & 41 & \\
\hline Pure glycerine & 19 & 53 & 47 & 0.0956 \\
\hline Pure oils & 11 & 45 & 55 & 0.0726 \\
\hline $\begin{array}{c}\text { Dermo-cosmetic } \\
\text { body lotion }\end{array}$ & 4 & 100 & 0 & $\mathbf{0 . 0 0 1 9}$ \\
\hline $\begin{array}{c}\text { Bleaching lotion } \\
\text { Ordinary moisturizing } \\
\text { body milk }\end{array}$ & 918 & 87 & 13 & $\mathbf{0 . 0 0 0 4}$ \\
\hline $\begin{array}{c}\text { Indeterminate } \\
\text { body lotion }\end{array}$ & 77 & 40 & 35 & 0.0521 \\
\hline \begin{tabular}{c} 
No body lotion \\
\hline
\end{tabular} & 92 & 16 & 84 & $\mathbf{0 . 0 0 0 1}$ \\
\hline
\end{tabular}

We think that in the tropical environment, daily body rubbing probably attenuates this irritability of the skin, but the precarious equilibrium of skin physiology is rapidly broken once the climatic conditions are modified. In our current study, it was observed that $12.20 \%$ of those who habitually used antiseptic soaps did not apply any body lotion at all. Some African authors have described an increase in the prevalence of atopic dermatitis and contact eczema to the detriment of infectious dermatoses that were formerly the most encountered $[7,8]$. Their explanation for this modification is based on an increased level of environmental allergens and nutritional factors. We however, suggest as a possible additional hypothesis to understand this phenomenon, namely, the habitual use of antiseptic products on the skin. Our finding of a high proportion of antiseptic soap users who presented with allergic skin disorders (35\%) especially eczemas lends some support to this hypothesis.

The use of bleaching agents is not uncommon in Yaoundé, as $13 \%$ of subjects were involved in our series. It is very likely that this figure is an underestimation of the reality, given the retrospective nature of our study, and that $12.38 \%$ of those who admitted the use of body lotion did not reveal the nature of the lotion. This latter attitude could be an attempt to conceal the use of bleaching agents as the

Table 5. Daily Skin Care Habits with Respect to Age (n=622)

\begin{tabular}{|c|c|c|c|c|c|c|c|}
\hline Age Group & $\mathbf{N}$ & Pure Glycerine (\%) & Oils $(\%)$ & Dermo-Cosmetic Lotion (\%) & $\begin{array}{l}\text { Bleaching } \\
\text { Lotion (\%) }\end{array}$ & $\begin{array}{l}\text { Ordinary Moisturizing } \\
\text { Body Lotion }(\%)\end{array}$ & $\begin{array}{c}\text { Undetermined } \\
\text { Body Lotion (\%) }\end{array}$ \\
\hline Total & 622 & 3 & 2 & 1 & 15 & 67 & 12 \\
\hline $0-10$ & 114 & 1 & 4 & 0 & 4 & 89 & 3 \\
\hline $11-20$ & 97 & 2 & 0 & 1 & 15 & 72 & 9 \\
\hline $21-30$ & 184 & 3 & 2 & 2 & 24 & 54 & 15 \\
\hline $31-40$ & 100 & 4 & 0 & 0 & 15 & 60 & 21 \\
\hline $41-50$ & 69 & 6 & 1 & 0 & 16 & 61 & 16 \\
\hline$>51$ & 58 & 5 & 2 & 0 & 7 & 78 & 9 \\
\hline
\end{tabular}

Table 6. The Use of Emollient/Moisturizing Body Lotions with Respect to Bathing Soap Type

\begin{tabular}{|c|c|c|c|}
\hline & n & $\begin{array}{c}\text { Antiseptic } \\
\text { Soap (\%) }\end{array}$ & $\begin{array}{c}\text { Bleaching } \\
\text { Soap (\%) }\end{array}$ \\
\hline \hline Total & 714 & 17 & 9 \\
\hline Pure Glycerine & 19 & 26 & 11 \\
\hline Oils & 11 & 18 & 18 \\
\hline Dermo-cosmetic lotion & 4 & 0 & 28 \\
\hline Bleaching body lotion & 93 & 18 & 7 \\
\hline Ordinary Moisturizing body lotion & 418 & 20 & 0 \\
\hline Indeterminate body lotion & 77 & 0 & 3 \\
\hline No body lotion & 92 & 16 & 0 \\
\hline
\end{tabular}

Table 7. Analysis of Main Complaints vs Additives to Body Lotion

\begin{tabular}{|c|c|c|c|c|c|c|c|}
\hline \multirow{3}{*}{ Main Complaint } & \multirow{2}{*}{\multicolumn{2}{|c|}{ Total }} & \multicolumn{5}{|c|}{ Additives to Body Lotion } \\
\hline & & & \multicolumn{2}{|c|}{ Yes } & \multicolumn{2}{|c|}{ No } & \multirow{2}{*}{$P$ Value } \\
\hline & $\mathbf{N}$ & $\%$ & $\mathbf{N}$ & $\%$ & $\mathbf{N}$ & $\%$ & \\
\hline Total & 714 & 100 & 126 & 100 & 588 & 100 & \\
\hline $\begin{array}{l}\text { Lesions of skin } \\
\text { appendages }\end{array}$ & 24 & 3 & 7 & 6 & 17 & 3 & 0.098 \\
\hline Acne & 55 & 8 & 16 & 13 & 39 & 7 & 0.025 \\
\hline Others & 25 & 4 & 5 & 4 & 20 & 3 & 0.561 \\
\hline Skin eruptions & 179 & 25 & 27 & 21 & 152 & 26 & 0.240 \\
\hline Pruritus & 322 & 45 & 57 & 45 & 265 & 45 & 1.000 \\
\hline Ulceration/scars & 51 & 7 & 5 & 4 & 46 & 8 & 0.117 \\
\hline $\begin{array}{l}\text { Pigmentation } \\
\text { disorders }\end{array}$ & 41 & 6 & 7 & 6 & 34 & 6 & 1.000 \\
\hline $\begin{array}{c}\text { Swelling/ } \\
\text { inflammations }\end{array}$ & 17 & 2 & 2 & 2 & 15 & 3 & 0.539 \\
\hline
\end{tabular}


Table 8. Distribution of Types of Additives to Body Lotion with Respect to Main Complaint

\begin{tabular}{|c|c|c|c|c|c|c|}
\hline Total & 126 & 2 & 11 & 2 & 72 & 12 \\
\hline Acnea & 16 & 6 & 13 & 0 & 63 & 19 \\
\hline Others & 5 & 0 & 20 & 20 & 40 & 20 \\
\hline Pruritus & 57 & 0 & 12 & 4 & 74 & 11 \\
\hline Ulceration/scars & 5 & 0 & 0 & 0 & 100 & 0 \\
\hline Pigmentation disorders & 7 & 0 & 29 & 0 & 57 & 14 \\
\hline
\end{tabular}

sentiment of guilt in users of these products is well described in the literature [9-12]. Several authors have described higher rates of use of this type of agents in Africa: 25 to $67 \%$ in the general population and 27 to $92 \%$ in hospital populations. The practice of bleaching agents, whose complications have been proven, constitute a public health problem in many countries $[2,3,8,10-12]$.

The tendency of patients to add other substances to emollients and commercialized moisturizers (17.7\%) is not specific to our context. This practice is not without risk as it may result in a product with a modified composition, not respecting quality norms. Many women in search of bleaching are familiar with this fact [2]. However, the proportion of those who added pure glycerin in our study sample was not negligible. This probably suggests an inadequacy between the products sold on the market and the cosmetic needs of black skin especially in terms of moisturizing characteristics. In spite of the efforts of producers to meet the needs of consumers with respect to products adapted to the black skin, the best cosmetics remain inaccessible [13], the majority of the population using products of lower quality making those who are unsatisfied to turn to artisanal preparations. Okeke had reported the insufficiencies related to the quality assurance of products available to consumers in Nigeria [13]. He emphasized on the high bacterial load of products from recognized cosmetic industries and the infectious risk they represent [13], especially with local compositions. Concerning the association of acne as a chief presenting complaint and the addition of topical corticosteroids in body lotions, a causal relationship is highly probable in our sample, given that this has been established in the literature. On the other hand, the observation that significantly more women than men had as chief complaint acne and pigmentation disorders, could constitute a justification for the use of inappropriate cosmetic products.

This preliminary study has some limitations for example: patients generally would not be able to give precise information such as duration of skin care habits. Another limitation is that the association of chief presenting complaints and cosmetologic habits may not have a causal relationship. Furthermore, as the study was conducted in a specialized department of a tertiary health institution, the results cannot be extrapolated to the general population. Nevertheless, the study provides the baseline for further work that will hopefully answer some of the many issues raised by the use of these skin modifying agents for habitual skin care.

\section{CONCLUSION}

A relatively high proportion of patients seen in the Dermatology outpatient clinic in Yaoundé use antiseptic soap and bleaching products, and this is done quite early in life. Furthermore, the addition of some harmful substances in commercial preparations by these patients may become a serious health problem if left uncontrolled. There is a need for more studies on these issues in our environment.

\section{REFERENCES}

[1] Smith W, Burns C. Managing the hair and skin of African American pediatric patients. J Pediatr Health Care 1999; 13(2): 728.

[2] Ly F. Complications dermatologiques de la dépigmentation artificielle en Afrique. Ann Dermatol Venereol 2006; 133: 899906.

[3] Gathse A, Obengui P, Ibara JR. Motifs de consultation liés à l'usage des dépigmentants chez 104 utilisatrices à Brazzaville, Congo. Bull Soc Pathol Exot 2005; 98: 387-9.

[4] Fitoussi C. Pathologie d'adaptation de la peau noire en France métropolitaine. Ann Dermatol Venereol 2006; 133: 871-5.

[5] Cabotin PP. Cosmétologie de la peau noire. Encycl Med Chir (Editions Scientifiques et Médicales Elsevier SAS, Paris, Cosmétologie et Dermatologie Esthétique), 50-220-110, 2000; p. 4.

[6] Pons-Guiraud A. Les cosmétiques et la peau, Edition du Rocher 1997.

[7] Nnoruka EN. Skin diseases in south-east Nigeria: a current perspective. Int J Dermatol 2005; 44(1): 29-33.

[8] Ogunbiyi AO, Daramola OO, Alese OO. Prevalence of skin diseases in Ibadan, Nigeria. Int J Dermatol 2004; 44(1): 31-6.

[9] Mahe A, Blanc L, Halna JM, Keita S, Sanogo T, Bobin P. Enquête épidémiologique sur l'utilisation cosmétique de produits dépigmentants par le femmes de Bamako (Mali). Ann Dermatol Venereol 1993; 120: 870-3.

[10] Raynaud E, Cellier C, Perret JL. Depigmentation cutanée à visée cosmétique: Enquête de prévalence et effets indésirables, dans une population féminine sénégalaise. Ann Dermatol Venereol 2001; 128: $720-4$. 
[11] Petit A. Prise en charge des complications de la dépigmentation volontaire en France. Ann Dermatol Venereol 2006; 133: 907-16.

[12] Petit A, Cohen-Ludmann C, Clevenbergh P, Bergmann JF, Dubertret L. Skin lighteningand its complications among African people living in Paris. J Am Acad Dermatol 2006; 55: 873-8.
[13] Okeke IN, Lamikanra A; Bacteriological quality of skin moisturizing creams and lotions distributed in a tropical developing country. J Appl Microbiol 2001; 91: 922-8.

Received: February 2, 2011

(C) Bissek et al.; Licensee Bentham Open.

This is an open access article licensed under the terms of the Creative Commons Attribution Non-Commercial License (http: //creativecommons.org/licenses/by$\mathrm{nc} / 3.0 /$ ) which permits unrestricted, non-commercial use, distribution and reproduction in any medium, provided the work is properly cited. 